\title{
El arte de andar en la naturaleza
}

\section{Artículo de investigación}

\section{María José Arbeláez Grundmann}

Universidad Distrital Francisco José de Caldas, Colombia lafabrica28@yahoo.com

Recibido: 12 de julio de 2017

Aprobado: 10 de septiembre de 2017

Cómo citar este artículo: Arbeláez Grundmann, María José (2018) El arte de andar en la naturaleza. Calle14: revista de investigación en el campo del arte, 13 (23) pp. 170-185. DOI: https://doi. org/10.14483/21450706.12997 


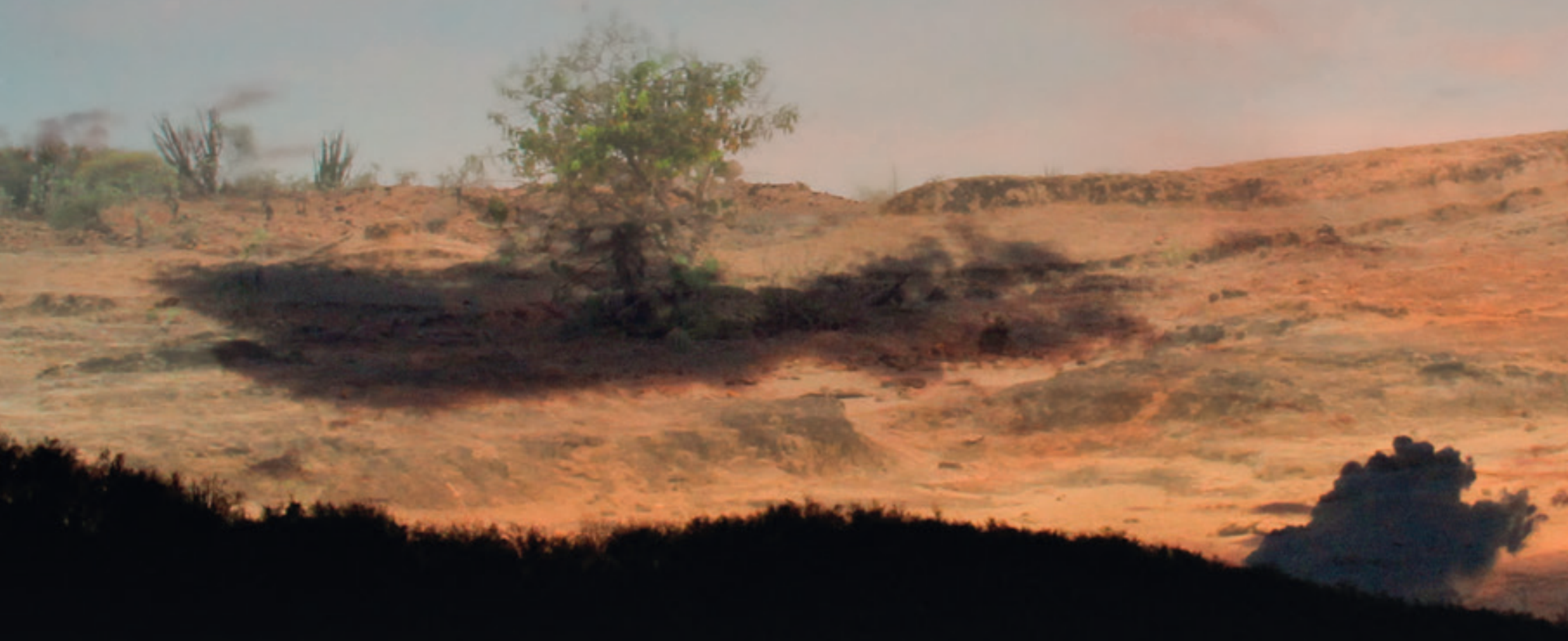




\title{
Resumen
}

El arte de andar en la naturaleza gira alrededor de la cuestión ética y política de, ¿cómo los hombres nos relacionamos con la naturaleza cuando recorremos caminos? La respuesta se nutre de la filosofía ecofeminista espiritual de Vandana Shiva, la cual considera, junto con comunidades indígenas, a la tierra como un ser vivo, con el cual el hombre tiene una conexión espiritual y no es solamente garante de su existencia mediante la explotación ilimitada. Se amplía la reflexión en torno a los modos de relacionarse el hombre con la comunidad de los seres vivos mediante la propuesta de la ética de la tierra elaborada por Carlos Alfredo Vargas. Como práctica artística y proyecto de investigación, el arte de andar es una experiencia vivencial cotidiana consciente en el caminar diferentes recorridos, durante la cual se establecen relaciones de diversos órdenes, explorando los procesos creativos a partir de sensaciones corporales gracias a la apertura del caminante a las fuerzas intempestivas que atraviesan y modifican su cuerpo, tomado como referencia el "cuerpo sin órganos", categoría desarrollada por Gilles Deleuze y Félix Guattari. El andar diferentes territorios permite la resignificación simbólica de los lugares, no necesitando expresarse en materialidades; por el contrario, esta práctica es tan respetuosa que solamente deja huellas móviles y evanescentes.

\section{Palabras claves}

Práctica artística, el andar en la naturaleza, la ética de la vida, la ética de la tierra, el arte como práctica artística vivida, el cuerpo sin órganos, filosofía ecofeminista.

\begin{abstract}
The art of walking in nature revolves around the ethical and political question of how do humans relate to nature when we walk in its paths? The answer is nourished by the spiritual ecofeminist philosophy of Vandana Shiva, which considers, along with indigenous communities, the earth as a living being with which man has a spiritual connection, and is not only the guarantor of his existence through unlimited exploitation. The reflection on the ways of relating man to the community of living beings is expanded through the ethics of the land proposed by Carlos Alfredo Vargas. As artistic practice and research project, the art of walking is a daily conscious experience in walking different routes, during which relationships of various orders are established, exploring the creative processes coming from bodily sensations thanks to the walker's openness to the untempered forces that pass through and modify her body (we take as reference the "body without organs" category developed by Gilles Deleuze and Félix Guattari). Walking different territories allows the symbolic resignification of places, which don't need to express themselves in "materialities"; on the contrary, this practice is so respectful that it leaves only moving and evanescent traces.
\end{abstract}

\section{Keywords}

Artistic practice, walking in nature, the ethics of life, the ethics of the land, art as a lived artistic practice, body without organs, ecofeminist philosophy.

\section{Résumé}

L'art de marcher dans la nature tourne autour de la question éthique et politique de la façon dont les humains se rapportent à la nature quand nous marchons sur ses chemins. La réponse est nourrie par la philosophie écoféministe spirituelle de Vandana Shiva, qui considère, avec les communautés indigènes, la terre comme un être vivant avec lequel l'homme a un lien spirituel et n'est pas seulement le garant de son existence par une exploitation illimitée. La réflexion sur les façons de mettre l'homme en relation avec la communauté des êtres vivants se développe à travers l'éthique de la 
terre proposée par Carlos Alfredo Vargas. En tant que pratique artistique et projet de recherche, l'art de la marche est une expérience consciente au quotidien de différents parcours, au cours desquels des relations de différents ordres s'établissent, explorant les processus créatifs issus des sensations corporelles grâce à l'ouverture du promeneur aux forces non tempérées et à la modification de son corps (nous prenons comme référence la catégorie « corps sans organes » développée par Gilles Deleuze et Félix Guattari). Marcher sur de différents territoires permet la re-signification symbolique des lieux, qui n'ont pas besoin de s'exprimer dans les matérialités ; au contraire, cette pratique est si respectueuse qu'elle ne laisse que des traces mouvantes et évanescentes.

\section{Mots clés}

Pratique artistique, marche dans la nature, éthique de la vie, éthique de la terre, art comme pratique artistique vécue, corps sans organes, philosophie écoféministe.

\section{Resumo}

A arte de andar na natureza gira em torno da questão ética e política de como os humanos se relacionam com a natureza quando caminhamos pelos caminhos? A resposta é nutrida pela filosofia ecofeminista espiritual de Vandana Shiva, que considera, juntamente com as comunidades indígenas, a terra como um ser vivo com o qual o homem tem uma conexão espiritual e não é apenas o garante de sua existência através de uma exploração ilimitada. A reflexão sobre as formas de relacionar o homem com a comunidade de seres vivos é expandida através da ética da terra proposta por Carlos Alfredo Vargas. Como prática artística e projeto de pesquisa, a arte da caminhada é uma experiência consciente diária na caminhada de rotas diferentes, durante as quais são estabelecidas relações de várias ordens, explorando os processos criativos provenientes de sensações corporais graças à abertura do caminhante às forças intempestivas que passam e modifica seu corpo (tomamos como referência a categoria "corpo sem órgãos" desenvolvida por Gilles Deleuze e Félix Guattari). Andar em diferentes territórios permite a resignificação simbólica de lugares, que não precisam se expressar em materialidades; Pelo contrário, esta prática é tão respeitosa que deixa apenas vestígios móveis e evanescentes.

\section{Palavras-chave}

Prática artística, caminhada na natureza, ética da vida, ética da terra, arte como prática artística vivida, corpo sem órgãos, filosofia ecofeminista.

\section{Maillallachiska:}

Kai suma purir sachakunapi tapurimi suma kagta i lidu kaskasina, ¿ imasami nukanchi karikuna rimanchi sachukupi i purispa? Kai aini kami sug warmikunapisina i sug ispirituwa kai suti runa Vandana Shiva, I kai kaiaiami nukanchi pura kunawa sug alpa imasami kaugsakuna, chasa runa ispiritiwa pudimi rimanakunga I chasaiatata runa pudimi kaugsanga sug animalkunawaspa chasa nispa kai runa suti Carlos Alfredo Vargaskai ruraikuna kami imasami rurarkasina i tapuspa i chasa iachaspa iacharimi imami iachaikuri kai kaugsaka Tukui punchakuna chasa kai pudirimi puringa sug chaimama i chasaiatata pudirimi uianga pimi mandaska, chasami iachaikuringa imasa kagta kai purripi i tsukanakuspa paipa kikinpa kuirpusina kai rachachiska runa suti Gilles Deleuze, Felix Guattari. Chasa sug alpapi ruraspi allikami ninga imasami chi luar kagta i mana ministinchu Rimangapa kai chasa kagta, i kai iachaikuipi sakimi achaka kawangapa.

\section{Rimangapa Ministidukuna:}

Imasami llunchiskapi ruraska purii sachakupi, sumaglla kaugsai, sumaglla alpapi karkasina, imasami rurariska kaugsaipi sug kuirpupi mana ñima chusa wigsapi, iuiachii warmisina. 


\section{Introducción}

La espiritualidad no es sino: el amor reflexivo por la vida, pues es un sentimiento de profunda conciencia y ternura, de identificación con el cosmos, con la naturaleza, con todos los seres y con el mundo.

Patricio Guerrero

El arte de andar en la naturaleza se torna tanto una práctica artística como un proyecto de investigación, realizado mediante varias salidas de campo efectuadas en algunas zonas de los departamentos de Cundinamarca y del Huila: el parque natural Chicaque, ubicado cerca de Bogotá; la cascada del Salto del Mico, ubicada en Villeta; el Camino Real de San Javier, en el municipio de La Mesa; la laguna de Iguaque, en Villa de Leyva; y el desierto de la Tatacoa, en el Huila. La pregunta crucial que nos hicimos como grupo investigador giraba alrededor de esta cuestión ¿cómo es la relación entre el hombre y la naturaleza en nuestra cultura occidental?, y más concretamente ¿cómo me relaciono con la naturaleza al recorrer caminos?

Buscando responder a tales preguntas, fue fundamental conectar la práctica del arte de andar en la naturaleza con la filosofía ecofeminista espiritual de Vandana Shiva (Aránzazu Hernández, 2012) la cual nutrió teóricamente la respuesta a la primera pregunta, dándole otro sentido, pues la filósofa realiza su reflexión en el accionar político-ético de la producción cotidiana de la subsistencia, alejándose de la visión que considera la naturaleza como materia inerte cuyo único fin es ser explotada.

Vandana Shiva resalta el trabajo que desarrollan la mayoría de las mujeres en el mundo, el cual ha originado un saber inmensamente rico sobre el sostenimiento de la vida. Este es un saber materialista, pues el trabajo de muchas mujeres con la tierra implica la comunión con un ser vivo con el que se establece una conexión espiritual, y que no solamente garantiza su propia supervivencia y la de sus semejantes. Esta apuesta centrada en la ética de la vida, que es una ética de la tierra, es un reconocimiento al compromiso que debemos tener para lograr la transformación de los conceptos, ideas y compromisos que regulan gran parte de las prácticas cotidianas de cuidado y sostenibilidad de la comunidad de todos los seres.

Por su parte, Carlos Alfredo Vargas en el texto Contrato ético con la naturaleza (2011) amplía la reflexión en torno a la palabra ética, ya no entendiéndola solamente como construcción o acuerdo de leyes y ciertos comportamientos que se dan entre individuos en la sociedad occidental; sino que su propuesta incluye dentro de este contrato a las múltiples comunidades de seres que habitan los diversos lugares. Esta comprensión es compartida por el Taita Isaías Román pertenenciente a la comunidad Uitoto del Medio Centro del Amazonas, quien, por medio de su palabra enseña sobre lo que existe en la tierra y en el cosmos, sobre historias relacionadas con el humano y otros seres, todo lo cual permite ir abriendo la comprensión y el corazón, para poder vivenciar cotidianamente estas energías y así poder organizarnos como humanos formando parte de una comunidad de un modo equilibrado.

En este proceso ha sido importante el aporte de los artistas teóricos Álvaro Moreno Hoffman y Dora Inés Munévar, los cuales, gracias al trabajo que desarrollan principalmente en el libro Artes Viv(íd)as, despliegues en la vida cotidiana, movilizan, amplian y nutren el significado del arte en torno al entendimiento de éste como una práctica artistica vivida cotidianamente gracias a la experienciación del existir mediante el cuerpo, la cual permite crear vínculos sensibles y afectivos con la naturaleza, los animales, los otros, los lugares y el cosmos.

Es importante mencionar que este texto contiene algunos de los escritos que realicé para la bitácora, y es una síntesis de las notas personales del trabajo de campo. Los modos de escritura no son estrictamente académicos dado que son narraciones libres y anotaciones personales sobre procesos y vivencias durante el período de tiempo en el que desarrollo este proyecto de investigación. También contienen palabra compartida de abuelas y de taitas con quienes he tenido el privilegio de departir algunas horas.

\section{El arte de andar como práctica artística viv(íd)a}

Dora Inés Munévar en su texto En mis Manos, y Álvaro Moreno Hoffman en su texto Maniobras, ofrecen saberes que permiten construir espacios nuevos unidos por la expresión estética desde la vivencia individual, alrededor del arte como experimentación del existir, de la unión del arte y la vida, de la construcción de sentidos en los territorios del vivir, de la vida como obra en proceso y de la obra como proceso. Estos conceptos nutren el vivir consciente cotidiano que me he propuesto académica y vitalmente, y alientan los posibles 


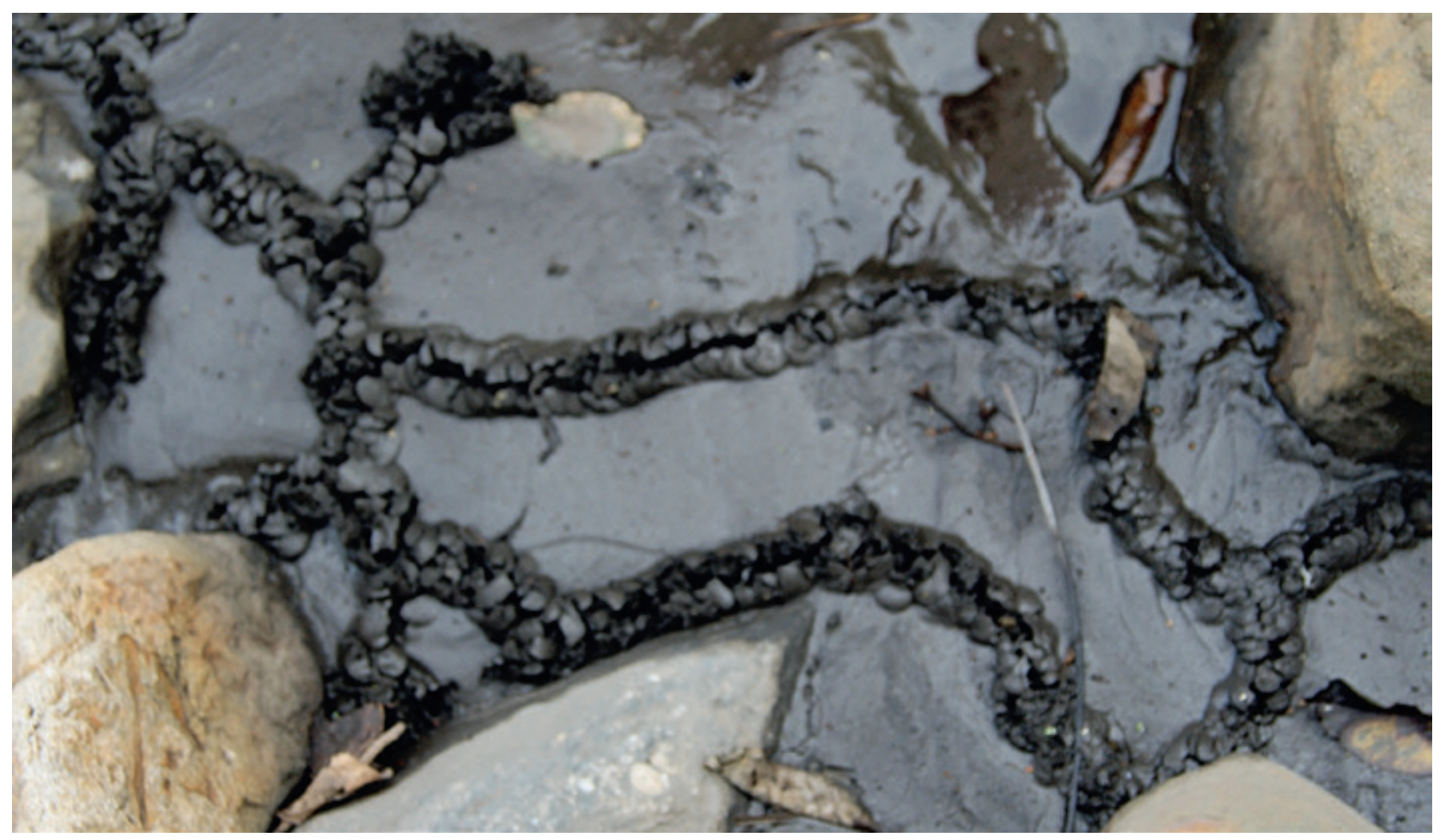

Cascada de los 7 monos, Villeta (2013). Fotografía: María José Arbeláez.

cambios vitales constituyendo una base reflexiva del arte de andar como práctica artística, y que es desarrollada en el proyecto de investigación, esta ha tenido un profundo sentido en mi vida, ha orientando la transformación y ampliación de mi conciencia y mi responsabilidad individual y colectiva para con el proceso de la vida. A continuación ampliaré algunas de estas ideas.

\section{Explorar la expansión del arte tanto como la expansión de la conciencia}

En la época moderna el arte se terminó dividiendo en disciplinas individuales, cada una localizada dependiendo de su medio o herramienta con la que se realizaba. El arte expande su campo cuando las diferentes disciplinas no están circunscritas en un solo territorio y la obra de arte comienza a ser una proyección individual fundida en la creación de un sueño colectivo; en este caso, el arte se propaga, está comprometido, se abre la conciencia, se sensibiliza ante la situación de la Pachamama, y por tanto, del compromiso a actuar en consonancia. (Guerrero, 2011).

\section{Cultivar la vida como obra en proceso}

Dora Inés Munévar propone la cotidianidad como el medio a explorar procesos creativos, a partir de sentires corporales y acciones con las manos centradas alrededor de cuestiones tales como: lo que se siente; lo que se ve; lo que se oye; lo que se percibe; lo que se contacta; y yo añado otros elementos a la experimentación cotidiana; los sentires sensibles, los perceptos, los encuentros. Quiero sentir e ir más allá de cómo me siento... y me pregunto entonces, ¿cómo vivencio mi entorno? Para responder a esto trato de sentir, de ver y de oír; en primer lugar, con mis múltiples canales perceptivos o dispositivos entrenados por la cultura; compartir desde el estado de observador neutral y el sentirpensar humano en relación con todos los seres.

¿Los cambios vitales son necesarios para cultivar la obra como proceso? Sí, están disponibles, abiertos, miedosos, corren tras; se entregan, deteniéndose, preguntándose, cómo realizo mi compromiso con mi cambio vital que a la vez implica tu cambio, y que conlleva al cambio de todos. Desde que se torna importante el cuestionamiento sobre la forma tradicional de vivir y de habitar en este planeta, con los conceptos y modos establecidos, he retado lo habitual, y así he comenzado y algunos han comenzado a romper muchas reglas. Me acompaña en este nuevo camino una nueva alianza con mi parte instintiva e intuitiva, que se fortalece con mi fuego interior, que se nutre con los olores, los sabores y la naturaleza. 


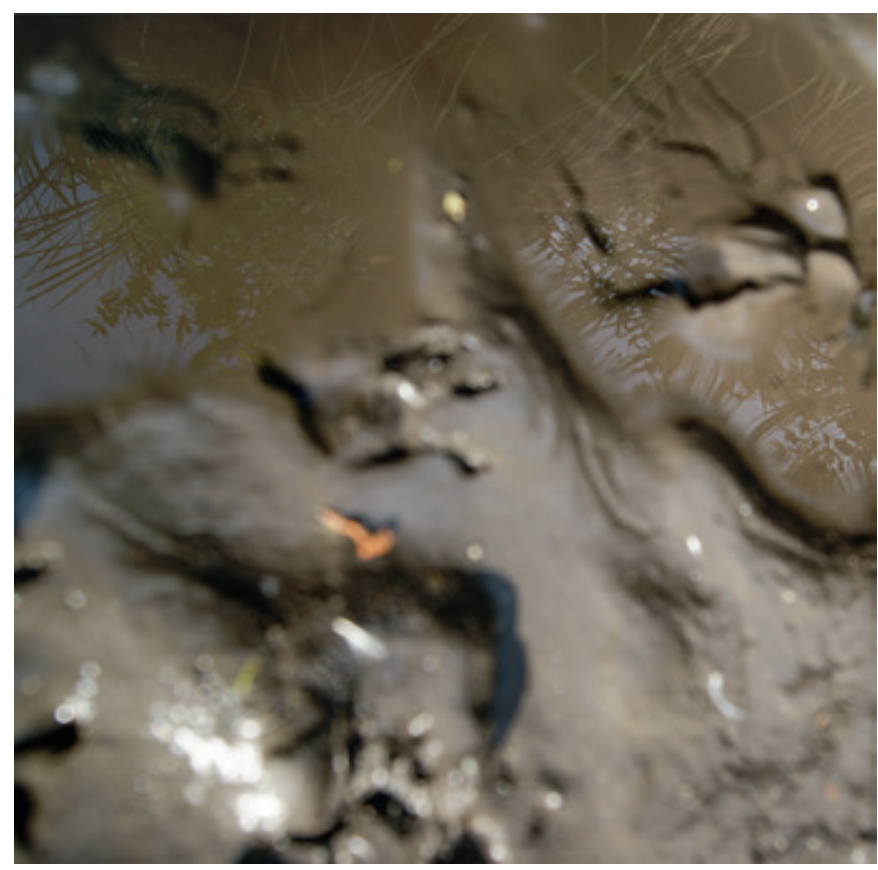

Cascada de los 7 monos, Villeta (2013). Fotografía: María José Arbeláez.

\section{Cultivar la obra como proceso}

Encontré sentido al proceso de cultivar una obra mediante palabras resonantes con los accionares transitados durante el tiempo vivido caminando rumbos geográ ficos y sensibles, algunos de estos son: los descubrimientos que permiten el deslumbramiento ante algo diferente; la eco-reflexión o rebote de una intuición aun no concreta pero perseguida; la huella-reconocimiento de pasos trazados; las transcripciones de motivos como necesidad de la autoexpresión; el adentrarse a trayectos inciertos y recorrerlos; los encuentros con los otros como vivencias de autoconocimiento y apertura a mundos; la modificaciones de la ruta establecida como formas de navegación con vientos de libertad.

\section{El arte de andar en la naturaleza}

El arte de andar en la naturaleza es una práctica artística realizada mediante la acción de andar que, como experiencia vivencial cotidiana conciente, permite habitar, crear y fortalecer vínculos afectivos y sensibles con la naturaleza, los animales, los otros, los lugares y el cosmos (Guerrero, 2011). Estas relaciones son construidas a partir de los sentidos visual, auditivo, olfativo, gustativo, así como el sentido kinestésico, el sensible, el territorial; tales relaciones exploradas mediante el asombro, el diálogo, el vínculo afectivo, la imaginación, lo simbólico y lo metafórico se despliegan en diferentes modalidades: en el caminar de modo nomádico; en recorrer lugares, en diálogos internos y con los otros; en la apertura al entorno, a las fuerzas intempestivas que transforman los cuerpos y los lugares.

Las diferentes experimentaciones y vivencias son libres, abiertas, no preestablecen fines determinados, ni esperan soluciones en la ruta escogida. Se trata de una experimentación personal, sin juicios ni categorías, diferente a cada momento aunque siempre anclada a la vivencia del recorrido y a la propia intencionalidad.

Esta práctica artística de andar estando inmersos en la naturaleza cuestiona tanto las vivencias propias y las compartidas, como los modelos de comportamiento social y cultural que han configurado la relación con la naturaleza, propiciando desde la empatía, la compasión y la responsabilidad un cambio de asunción de la realidad. Como mujer conciente de la necesidad de transformación propia, como de la construcción de interrelaciones diferentes con todos los seres vivientes entre ellos la naturaleza, a fin de lograr proyectarnos como un tejido, hacia la urdimbre cósmica de la existencia.

Las sabidurías indígenas de América han sabido conversar con la espiritualidad de la naturaleza y el cosmos, han encontrado y han honrado los espíritus que habitan las plantas, los animales, las montañas, los océanos. Es en ese sentido que, desde nuestro proyecto, sentimos la necesidad de levantarnos a palpar el color y sabor que trae el día, en el tejido con la iluminación del sol, la temperatura de nuestro hogar, las nubes que pasan; el éxtasis ante el momento presente creado por nosotros mismos; la recreación de las actividades cotidianas vividas desde lo conciente; el amoroso cuidado y respeto entre todos. La práctica artística de andar en la naturaleza tiene un eco mucho más amplio que rebasa el ámbito del fenómeno artístico.

El centro de mi práctica artística radica en la unión vital de lo ético, lo político y lo artístico (al decir de Joseph Beuys) ya que la política concebida como la fuerza de luchar por la vida no la podemos entender sin los valores de carácter social que deben ser comunes, como la libertad, la justicia y la igualdad, y tales deben ser compartidos con todos los seres vivos, incluyendo a la naturaleza. Al comprometernos con las transformaciones sociales, culturales e históricas de nuestra realidad y de nuestro entorno necesarias en el momento actual, nos incluimos como agentes activos en ellas a través de la responsabilidad de las transformaciones del hombre de actuar de acuerdo al bien común, más 
allá de los intereses particulares, como también de las transformaciones en nosotros mismos consistentes en construir formas distintas de pensar, decir, actuar como seres sensibles frente a la vida, lo cual implica también un abordaje distinto del territorio, distinto del sistema y que se aleja de la concepción dualista occidental.

Complementando lo anterior, afirmo, siguiendo a Duchamp, que el arte debe tomarse como filosofía crítica desde la experiencia vital: Lo que le da al arte y al mundo su significado, es la experiencia del ser humano. Esta experiencia evoluciona, se actualiza y cambia con cada ser humano y con cada época, de modo que así se transforman los parámetros con los cuales nos relacionamos los hombres con el mundo y el cosmos.

Es de anotar que en el momento de realizar esta práctica artística nos sentíamos cercanos al modo de andar de los artistas caminantes Richard Long y Hamish Fulton y las reflexiones que se desprendían de su propuesta, puntualmente el hecho de que el artista se conecta, se abre al entorno y cuida del lugar en su caminar. Este accionar ético derivado de su propuesta nos invita a asumir la responsabilidad que tenemos como seres humanos en relación con la comunidad de seres vivos en todo territorio de la diversas existencias.

\section{El arte de andar en la naturaleza}

La Abuela Blanca Nelly Rativa ${ }^{1}$ dice: "en mi caminar y saliendo a varios lugares, le pregunto a las plantas, a las tierras, a los soles, cómo iba yo a sanar desde mi responsabilidad. Y comprendí que a lo largo del camino uno va sanando, porque somos luces".

En el proyecto: el arte de andar en la naturaleza, se realizaron seis salidas de campo en algunas zonas de los departamentos de Cundinamarca y el Huila: el Parque Natural Chicaque, ubicado cerca a Bogotá; la cascada del Santo del Mico, ubicada en Villeta; el camino Real de San Javier en el municipio de La Mesa; la Laguna de Iguaque en Villa De Leyva; y el Desierto de la Tatacoa, en el Huila.

1 Abuela Blanca Nelly Rativa, princesa MuisKa. Territorio BaKatá Medicina que porta tejido, canto, danza y poesía. Poder femenino desde el útero, consejo espiritual, limpieza de útero y acompañamiento en pagamentos.

\section{El viaje}

Como grupo de trabajo no preparábamos exhaustivamente las salidas, es decir, el proyecto tenía determinados los lugares por donde íbamos a caminar, pero estaba abierto también a las eventualidades del momento. Buscábamos los sitios en la web indagando sobre su existencia, como también sobre las rutas o caminos reales; empacábamos las mochilas escogiendo nuestras ropas dependiendo del clima donde íbamos a estar, acordábamos una cita en el terminal de transporte de Bogotá y eso era todo.

Cuando llegábamos a la zona escogíamos los caminos, veredas y/o carreteras por donde íbamos a andar a pie, hicimos pequeñas caminatas o grandes paseos por el campo; caminábamos durante días y horas, recorriendo a pasos grandes o deteniéndonos; teniendo puntos marcados a donde llegar o dejándonos llevar por la intuición; tomando conciencia que cada camino y cada día de camino contiene en sí mismo múltiples posibilidades, como también que mientras se realiza la caminata estamos continuamente expuestos a lo insólito, al riesgo. Cada instante era un momento nuevo y particular que nos permitia ir elaborando una geografía de lo real en nuestro transitar.

En mi bitácora escribo

[...]después de andar un trayecto vemos a lo lejos el río Magdalena haciendo una gigantesca curva dorada sobre la planicie del valle que tenemos en frente, abertura acuosa oscura con reflejos en las diferentes capas formadas por los humedales, ya que estamos en época de lluvias, es octubre. Hoy en día, sentirme caminando en la tierra bajo el azul del cielo, la noche estrellada, el olor de hierbas, de todas las cosas de la tierra, es un asunto importante en mi vida. Llueve de todo en este territorio, cielos estrellados, agua a torrenciales, viento, tierra movediza, calor, tranquilidad y cariño se me presentan. Un sitio para estar. No valía la pena pensar en madrugar para emprender camino, pues llovía a cántaros. La situación era de escucha: los cantos variados de los pájaros, el aullido de los perros y el quejido de los cabritos sacrificados por los campesinos en esta mañana inauguran el día. (Bitácora 2015).

\section{Recorriendo los caminos}

La práctica de andar recorriendo un sitio específico la realizo cuando doy un paso tras otro paso de manera 


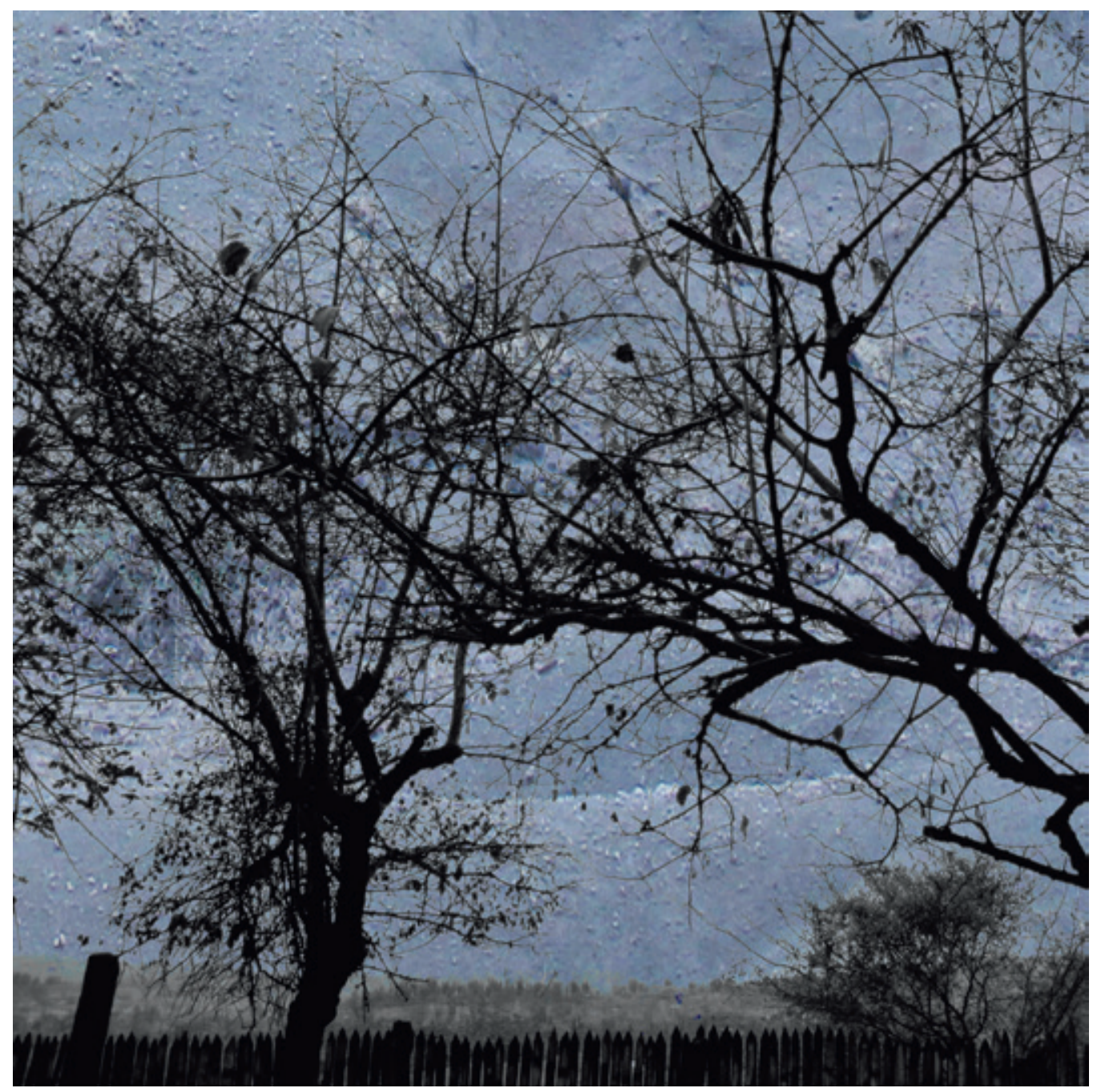

Desierto de la Tatacoa (2014). Fotografía: María José Arbeláez.

conciente, atravieso los lugares con atención concentrada en los pequeños hechos refinados (Serres), libero la mente, escucho mediante el silencio de las palabras, soy gracias al éxtasis de contemplar, vivo la luz de los espacios, vibro en la empatía hacia los animales que encuentro; siento mi cuerpo y lo habito en los llamados intuitivos, en el contemplar las nubes que pasan, en el existir, en el no hacer, en la fuerza del viento, en la luna que me inunda con sus efluvios, en la simplicidad, en la bondad de la vida, en la paz de mi interior.

¿Cómo caminamos? Recorremos caminos cortos y recorridos más largos de 5 o 6 horas. Salimos por la mañana y recorremos, paramos cuando estamos cansados o queremos pintar en algún lugar. No hay un método predeterminado y los caminos son diferentes. El camino está hecho de material y de acontecimientos, hay caminos de agua, de piedra y cemento, de tierra, de barro, de raíces de tronco, trazados, hechos por los indígenas, caminos sin huella, camino de paredes, caminos de hojas secas, caminos trillados.

¿Cómo se camina de un punto a otro? ¿Acaso se camino por senderos tortuosos o paradójicos? Hay caminos que no siempre se fijan y uno se guía por lo identificado en cada una de las cosas. Para transitarlos debemos cambiar permanentemente de posición, de lugar, de altura, conformando el espacio a partir de vistas caleidoscópicas. El placer de la contemplación eleva el espíritu a sentimientos que envuelven el alma, permaneciendo dormidos hasta que son nuevamente despertados gracias a una sensación vivida. Entre lo cercano y lo lejano queda el verde rodeado de montañas, la ruta escogida se torna irrelevante, el camino elegido se establece de acuerdo con los puntos cardinales, oriente, izquierda, norte...

Las situaciones pueden conducir al trazado de rumbos orientados por vientos que despiertan los sentidos, la 
percepción, los sentimientos, la conciencia crítica, la sensibilidad y la experiencia, como también la observación de cada uno de nuestros propios pensamientos y sentires. La meta en el andar está fundamentada en la creación de sentido y la reapropiación de significados, permaneciendo conscientes que la ocupación está apoyada en la libertad, en la creación, en la vida misma; y obliga a tomar diversos, diferentes y múltiples rumbos. Con el andar se desarrolla la imaginación, se educa la intuición y se apela a la improvisación. Este hacer no es desordenado y sin sentido (Munévar), sino este hacer necesita de una preparación interior y anterior.

Como escribe Serres en los Primeros Vientos (1984), un camino se realiza fácilmente cuando el caminar trascurre en medio de colores percibidos; hay espacios en blanco, descripción de la percepción de una vivencia en donde existe una franja neutra, no perteneciente a ninguna de las orillas del espacio, es decir, no se perciben límites. Este espacio en blanco es inexplorado y nuevo en las cartografías. Ninguna línea separa la tierra del cielo, no existe distancia intermedia, perspectiva ni contorno, la visibilidad es ilimitada; se da una topología extraordinariamente fina que no se basa en puntos $u$ objetos sino en conjuntos de relaciones de los elementos naturales existentes como son los vientos, los sonidos, los colores, las ondulaciones de la nieve, las olas de arena. Este es para Serres, el espacio de los tránsitos, transparente y virtual, tan arcaicamente conocido por los errantes, inmemorial como el desierto que se atraviesa también en el caminar nomádico de la mente, cuando comienza a construirse un conocimiento. El rumbo es la dirección del camino a recorrer, mas no es el sendero recorrido. El rumbo indica la posibilidad de escoger una dirección.

"El acto de andar, si bien no constituye una construcción física de un espacio, implica una transformación del lugar y sus significados. Solo la presencia física del hombre en un espacio no cartografiado, así como la variación de las percepciones que recibe del mismo cuando lo atraviesa, constituyen ya formas de transformación del paisaje que, aunque no dejan señales tangibles, modifican culturalmente el significado $y$, en consecuencia, el espacio mismo". (Careri. Francesco, 2002).

\section{Cartografías y diarios de campo}

El método de investigación-creación de este proyecto es cualitativo, es una práctica artística que se realiza a partir de las vivencias cotidianas como medio de explorar e identificar procesos relacionados con experiencias corporales, mentales, sutiles, instintivas, espirituales en el vivir experiencial sensible y afectivo que atraviesa nuestro cuerpo. En oposición a un cuerpo sólido, jerarquizado y dividido en sistemas, nos abrimos a una visión de cuerpo polivalente y mutable, "Cuerpo sin organos" categoría desarrollada por Deleuze y Guattari en su libro Mil mesetas, la cual señala un conjunto de prácticas realizadas por el hombre sobre su cuerpo. El cuerpo propio pasa de ser considerado instrumento de conocimiento u objeto, puesto que, antes de cualquier conocimiento, somos en el mundo, pasamos a ser un activo partícipe, absolutamente indispensable en su apropiación, pues somos sujetos en él, gracias a nuestro cuerpo. La sensación es pensada como fuerza intempestiva, realidad intensa que posee diferentes órdenes que atraviesa el cuerpo en una construcción no reflexiva del mundo.

En el ejercicio de andar se hacen actividades de observación: tomar notas, dibujar, fotografiar, llevar un cuaderno de campo; también se escriben las reflexiones a partir de un diálogo con las lecturas hechas y los encuentros y vivencias en los recorridos. Actuamos como observadores-participantes, apoyándonos en la descripción de lo percibido, vivido y experimentado como modo de recoger la información de cada una de las salidas. Estas notas son en su mayoría vivencias subjetivas y comentarios personales sobre lo acontecido. No se hacen críticas o análisis sobre lo visto. Es claro que en este proyecto no analizamos las notas de campo para hacer interpretaciones o construcciones de sentidos de vida y del mundo de los lugares visitados.

Personalmente, realizo las salidas de campo con la pregunta o tema que vengo meditando, como, por ejemplo, para la salida a la Mesa, me propongo percibir y sentir desde el vacío de pensamiento y de conflicto y me pregunto ¿qué significa fundirme en la naturaleza teniendo una cámara fotográfica, que me encuadra el paisaje con cierta estética normativa? Subiendo a Iguaque, la pregunta formulada fue, ¿qué es ser mujer? Como hoja de ruta del reconocimiento del territorio propio. Al realizar el viaje a Villeta, viví desde el recuerdo de, Solo soy una nube blanca que flota (Osho). En el viaje al Desierto de la Tatacoa, la materia a trabajar fue el tema de los miedos generados en mi interior y que reflejan el exterior que veo.

Después de realizar la bitácora y el cuaderno de notas de campo caí en cuenta que sentipienso (término creado por S. de la Torre (1997) que traduce un proceso de fusión y de integración del "sentir-pensar", asociado 
a otros impulsos básicos como persistir, interactuar, actuar, comunicar.) y tejo los recorridos desde seis diferentes elementos, los cuales son: estado de observación y escucha de mi cuerpo y los acontecimientos que suceden a mi alrededor; los animales que me acompañan o encuentro en cada uno de los recorridos; el mundo mágico que existe y me habla; las maticas y sus propiedades; el reconocimiento del territorio propio; los elementales en mis recorridos, y, finalmente, sé que quedan solamente las huellas móviles y evanescentes.

También, establezco un diálogo entre los elementos, el cual no está realizado con categorías delimitadas en sus territorios, ni obra jerarquización entre ellos, sino que se establece como una red de conexiones, sin orden, no controladas desde la razón, una amalgama entre las cosas, las personas y los acontecimientos. Tal y como dice Calvino (1989), el conocimiento del mundo se presenta como "la presencia simultánea de los elementos más heterogéneos que concurren a determinar cualquier acontecimiento (como también ...) en tanto infinitas relaciones, pasadas y futuras, reales o posibles, que en ellas convergen".

Enseguida paso a dialogar con los elementos que surgen:

a. Los diferentes espacios naturales los camino en estado de observación y escucha de mi cuerpo y de la naturaleza. Así puedo oler las hierbas, la tierra; sentir mi cuerpo, los cambios del clima, el polvo de los caminos, lo pesado del barro, el cielo blanco, azul, rojizo; las fuerzas emocionales de las personas que encuentro en el camino y los animales con los que coincido momento a momento. En este sentido, el espacio está hecho de acontecimientos, se sienten las fuerzas y los movimientos intempestivos que atraviesan y determinan cambios en el trayecto. El espacio es percibido a través de la intuición y la sensibilidad, está ligado a las afecciones. Aunque, a veces, también camino por un camino ya codificado, por unos trayectos ya realizados anteriormente, los cuales posibilitan la orientación.

Crear, percibir, organizar, construir un mundo del orden de las intensidades y de las fuerzas afectivas, devenir animal como forma espacial, tal y como lo entiende Deleuze, es situar el arte como semiótica ${ }^{2}$ y operación

2 Mas la teoría del sentido se desprende de toda referencia a la semántica: en el nivel de señales materiales, las circulaciones de afecciones y de afectos disponen de modos creadores (mundos animales) que seleccionan o producen señales (perceptos) y respuestas motrices, variaciones de potencia (afectos). vital tributaria de una territorialización expresiva, denominada ritornelo. Se concibe la creación como permanente evolución de devenires atravesados por fuerzas de distintos órdenes (fuerzas del caos, fuerzas terrestres y fuerzas cósmicas), en donde, la sensación tiene lugar como realidad intensiva en el cuerpo.

También escribo sobre mi cuerpo y mi transitar cuando subí a la laguna de Iguaque. Lo documenté así:

\section{Me uno completamente con la tierra} desde el tacto conozco que es mi carne no puedo transitar sino por los bordes del camino el tocar es agradable

mi cuerpo se flexibiliza mientras subo el estrecho camino hecho de barro, agua, tierra, piedras y raíces

de árboles y matas que impiden ver la montaña y el cielo

es blanda, cambia de forma, no tiene límites

definidos, es variable

recorro un camino hondo-estrecho

es misteriosa y enigmática

mis piernas se agarran fuertemente

se muestra, pero se oculta

siento dónde coloco un zapato enseguida del otro es de diferentes rojos, rosados, claros oscuros pierdo el equilibrio en medio de una carcajada o de un gran susto

de formas curvas y redondas

para nosotros, esta caminata se llamó el arte

de andar patinando

es dulce, bonita, bella

seguí subiendo por un camino difícil en donde

a veces perdí el sentido del caminar. Me preguntó para qué sigo subiendo, a dónde tengo que llegar y si renuncio y me detengo aquí necesita de cuidado y protección sigo con mi propósito y decido dar el último paso siento la sed, siento mis rodillas bloqueadas veo los árboles tan cercanos.

\section{b. Animales que me acompañan o encuentro en cada} uno de los recorridos. Como escribe Serres (1984), somos viajeros naturalistas explorando regiones concretas del mundo, desplazándonos a lugares en donde existen diversidades de clima, de biosfera, de fauna y flora; esto ha permitido la construcción del atlas de los seres vivos, por medio de una clasificación, organización, denominación, encasillamiento. Cada lugar tiene sus leyendas e historias dando lugar al mapa de la excursión. 


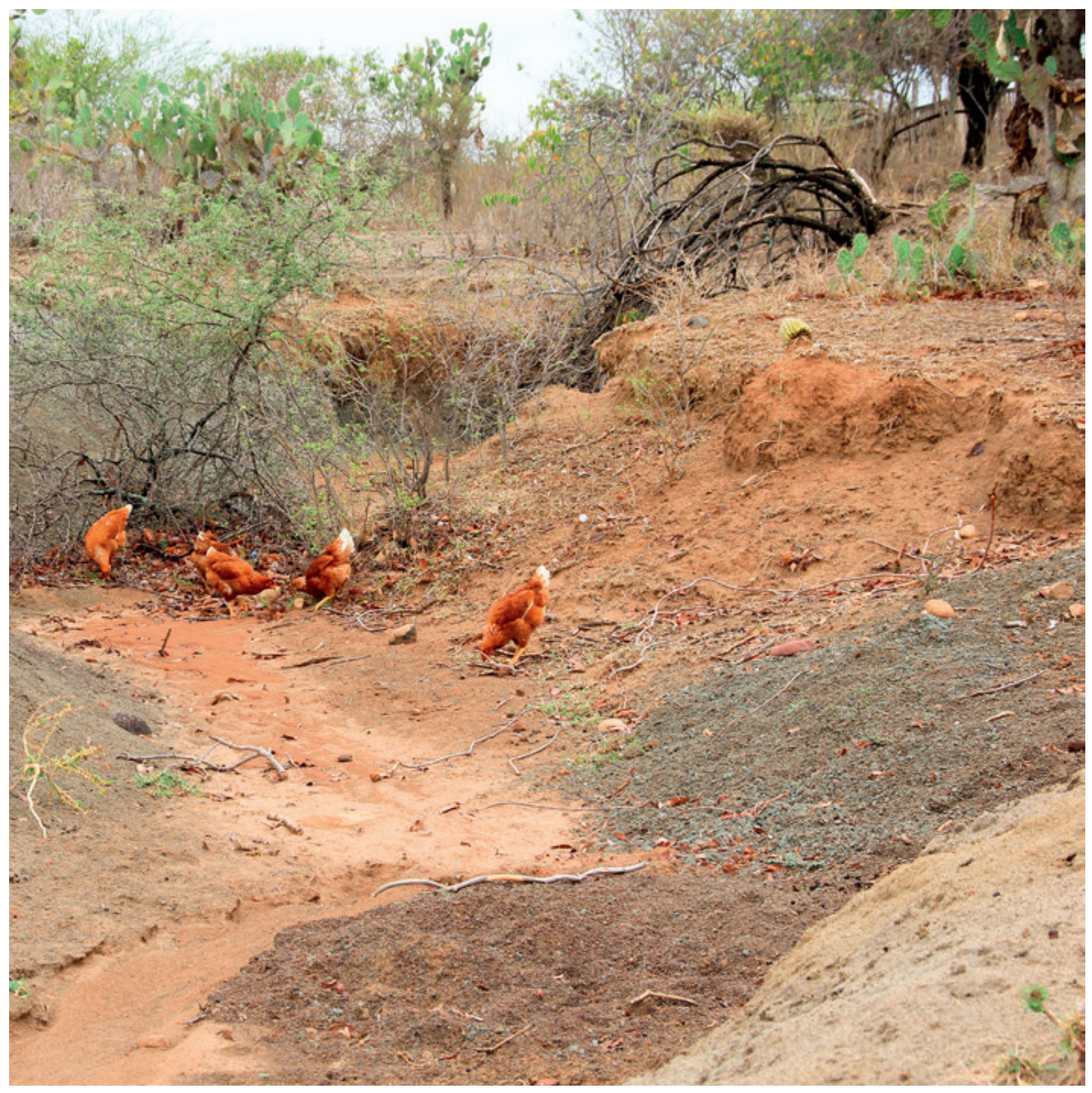

Desierto de la Tatacoa (2014). Fotografía: María José Arbeláez. 
Los encuentros con los animales permiten reflexionar sobre los presupuestos de órdenes establecidos tradicionalmente en relación con ellos, preguntándome cuando pasamos por un criadero de gallinas: nos miramos asustados, sobrecogidos, en silencio, viviendo el ruido agudo, los chillidos y la situación de estar en la situación de la gallina. iQué vida tan desesperante le hemos creado a la gallina...i y contribuimos permanentemente a que continúe; la energía sonora del dolor nos golpea, la situación de sufrimiento de los animales se hace evidente. Hablamos sobre nuestra relación con los animales que hemos domesticado como humanos. Algunos de ellos los acompañan en sus caseríos y gracias a ellos viven los hombres.

En el desierto de la Tatacoa, la familia campesina en donde nos hospedamos mostró un cariño maravilloso para con nosotros y para con sus animales. Mijo, mijo, venga tome su tetero. Venga mijo córrase de allí. Así dialogaban con los bebes cabritos que se encontraban acostados y juntitos debajo de la mesa del comedor durante el tiempo que tomamos el desayuno. El tetero del uno y luego el del otro lo daba el señor de la casa, grande, corpulento, pero atento de su familia. Volteando la mirada a raíz de unos chillidos agudos, y no más lejos de dos metros, otros hombres de la casa estaban matando los cabritos de dos o tres años para su almuerzo, compartir la carne y con el resto sacar ganancias.

\section{c. Cómo es la vegetación de cada uno de los espa-} cios recorridos. ¿En qué consiste la maravilla de haber creado este momento? Andar en medio del campo, contemplar, beber el agua. El sol del mediodía está fuerte. Hay flores consideradas espectaculares por sus curvas y sus formas, otras flores sentidas como cosas triviales pero que son tan mías, tan cotidianas a mi vista, siempre las encuentro en todas partes, como los pájaros que habitan en el mundo entero, así mismo, es el besito, esa flor que en todas partes alegra con su color.

\section{d. El mundo mágico existe y me habla}

un gatito me maulló y luego me mordió un hombre con el rostro quemado

llegó en moto vendiendo ruda un perro galgo negro atravesó mi camino En este instante descubro parte de mis miedos como mujer.

e. Las maticas y sus propiedades. Todo comenzó a partir de sentirme estresada y de la necesidad de ir a la plaza de mercado del 7 de agosto a donde las yerbateras, a fin de pedir matitas para calmar mi angustia, sentía que me transformaban los alimentos que consumía y con los que me bañaban. Fue claro también que esta experticia tenía que darse en un proceso de experimentación personal. Así fue también mi relación con la ruda, planta de poderes mágicos especiales, quien limpia mi cabeza de animales internos y externos.

f. Don Juaco vive en el desierto de la Tatacoa, señor y abuelo de su familia, nos dio unas recetas realizadas con plantas medicinales para descargar el hígado. Hierbas: Paraguay, hierba de trenzas y toronjil. Comprar nueve porciones de cada una de las hierbas y tomar durante 9 días. Este remedio sirve para botar gusanos verracos.

Y un remedio para el cabello y la ulcera gástrica Hierba. Cola de caballo.

Estos remedios se pueden utilizar con toda seguridad pues ya han sido ensayados por su autor, recalca el abuelo.

g. Los elementales en mis recorridos. Comenzamos el recorrido caminando en medio del río. Mi cuerpo es atravesado por el frescor del agua fría fluyendo en pequeños filamentos de la cabeza a los pies, de los ojos a la boca... me veo, soy un cuerpo sin pies, recorriendo un camino a ciegas, sin sostenerse por ningún bastón. En esta hermosa gruta verde miramos de cerca a las mariposas, no pisamos las hormigas, nos detuvimos a observarlas. Estamos conectados entre todos, con la luz del sol, los árboles, la brisa que me roza y me refresca trayendo gotas de agua; me rio con mi hija que está a mi lado, ese ser maravilloso con el cual estoy compartiendo hoy mi vida. En este instante, escucho la pregunta de mis maestras: ¿el camino es para recorrerlo? o ¿La vida es para vivirla?

En el viaje a la mesa anoto: el maestro es el viento. En la naturaleza, el viento dispersa las nubes acumuladas, permitiendo ver el cielo como una tintura azul clara y serena. El viento refresca mi piel y toca suavemente mi cuerpo. El viento se detiene mientras, pegada al borde de la carretera, subo la colina. La primera sensación que me golpea como una línea de fuerza en mi cuerpo es el miedo; la segunda embatida está formada por el ruido de la radio a alto volumen y la visión repleta de objetos abandonados y sucios a la orilla del camino. Me encuentro con unos niños jugando, me observan fijamente; hay también adultos que me miran, escucho su interrogación: ¿qué hace ella aquí, qué busca, estará perdida? Yo invado, incursiono, juzgo con mi mirada. Los perros y mis pies son mi protección; los perros me 
defienden de toda posible agresión, y a mis pies, los siento abriéndose, desplegándose, anclando uno a uno los dedos como enormes garras, los músculos de mis piernas se templan todo lo cual me permite sentirme segura en mi ágil subida, atravesando un territorio extraño para mí. !!Uff!! Llegué a la cima de la montaña la capa de mis emociones que me envuelve se evapora ante el reconocimiento de un nuevo lugar donde finalmente me encuentro situada.

\section{La ética de la tierra}

La pregunta ¿cómo me relaciono con los seres humanos y no humanos?, es planteada por la comunidad Uitoto de la Amazonia Colombiana, en contraposición a la pregunta realizada por la cultura eurocéntrica, la cual es, ¿quién soy yo? La cuestión fundante ética que nos proponemos abordar en el proyecto de investigación está en consonancia con la visión de los indígenas de la Amazonía.

El hombre vive en este planeta como sociedad consumista y capitalista, cuya finalidad última es el mercado, y considera a la naturaleza, los animales y la mujer como objetos débiles a los cuales es preciso dominar y dirigir mediante una inteligencia agresiva que se relaciona eminentemente con una visión errónea de lo masculino. La naturaleza ya no es considerada como materia viva y nutricia, se eliminan los supuestos de carácter animista y orgánico acerca del cosmos (Merchant, 1980); y la naturaleza se transforma en materia muerta, inerte y manipulable, sostenida por fuerzas que no le pertenecen a los lugares, siendo muy conveniente esta concepción para la explotación que exige el capitalismo en expansión. (Hernández, 2012). En el mismo sentido de la restringida tradición occidental, a los otros seres vivos no humanos se les considera como seres sin sentimientos, ni emociones; no se consideran sujetos intencionales, por lo tanto, pueden ser producidos, reproducidos y utilizados como el hombre los necesite y quiera.

Por el contrario, la tierra es el hogar sagrado en el sentido profundo para las comunidades agrícolas, ya sean indígenas o campesinas. El suelo es el alma de la sociedad, fuente de todos los significados y del sustento material y espiritual. La pertenencia a un lugar para una comunidad es de vital importancia, ella habita un lugar, reproduce su vida cotidiana en estrecha relación con la naturaleza, construye sus simbologías y significados culturales y espirituales en este espacio y conforma la memoria, el mito, la historia y las canciones que componen la vida diaria.

Habitar, vivir o morar en un lugar, lo cual implica cuidar del territorio en que se vive, (Vargas, 2011) significa etimológicamente la palabra ética. Siendo fieles con éste significado, vemos que incluye otras relaciones más allá de las solamente humanas. Como dije anteriormente, cuidar el territorio donde habitamos significa para las comunidades indígenas colombianas, cuidar el lugar donde vivieron los antepasados, en donde están enterrados, donde se realizaron las ceremonias, en donde viven los animales que compartieron este habitar, y donde nacerán las nuevas generaciones. El territorio no es solamente un lugar humano, sino un lugar de comunidades de seres habitando juntos en un principio de armonía. Por ejemplo, el ser humano cuida, sembrando para dar alimento, dice el Taita Isaías Román: “yo siembro para mi familia y tengo en cuenta también, los animales que habitan el lugar, pues ellos exigen su ración". Para estas comunidades en la tierra cabemos todos, animales, plantas, seres humanos, elementales; mundos etéricos y espirituales, antepasados, estrellas, todos habitando y entre todos cuidando en un aquí y un ahora, las múltiples comunidades que terminan cruzándose en los diferentes lugares en donde nos encontramos.

Para dar cabida a un cambio en el modo de relacionarnos con la naturaleza es necesario una transformación de pensamiento dentro de la comunidad de los seres humanos, a la cual nos acercaremos desde la filosofía de Vandana Shiva (Aránzazu, 2012). Ella desarrolla su propuesta basándose en la antigua cosmología de la India, la cual considera a la naturaleza, como proceso vivo y creativo denominada Prakriti, principio femenino ${ }^{3}$ del cual surge toda la vida y garantiza la supervivencia del humano y sus semejantes.

Dice la filósofa india que los seres humanos venimos de la tierra, de ella nos nutrimos, nos da la vida y volveremos a ella. Nosotros le pertenecemos. Está comprensión de la naturaleza como principio femenino crea la imagen de la tierra, como un hogar ecológico y espiritual. La imagen de hogar está lejana de la idea de progreso de Occidente, del progreso en sentido lineal; o también de entender el progreso de un hombre porque

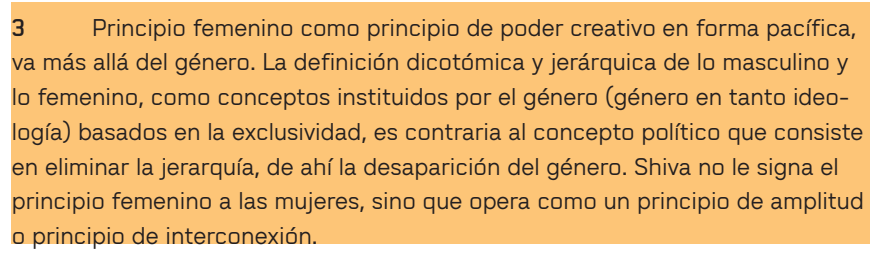



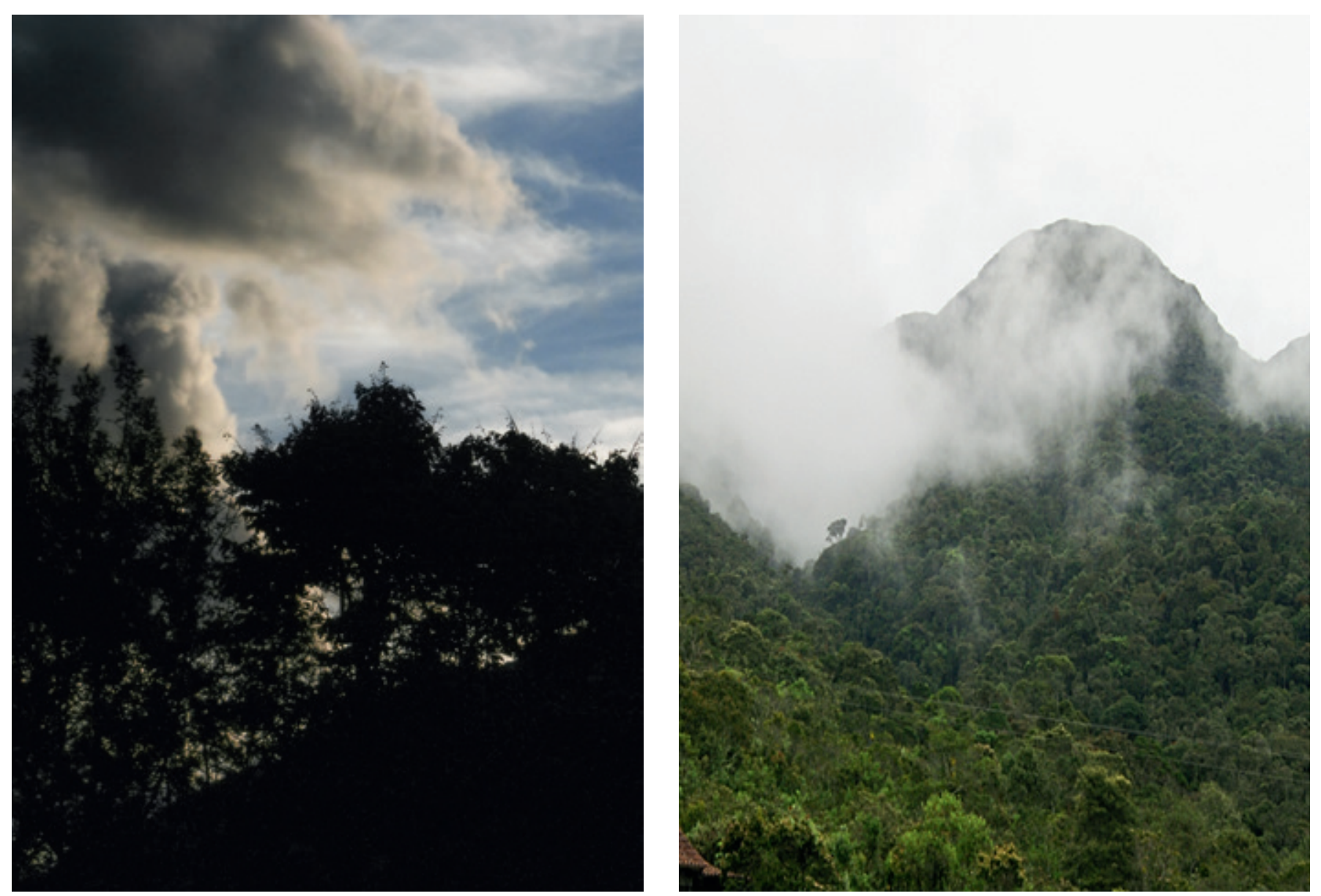

Villa de Leiva (2015). Fotografía: María José Arbeláez.

cambia constantemente su hogar cultural. Por el contrario, para una comunidad indígena no existe la idea de progreso, pues ella está amarrada espiritualmente a la tierra por sus antepasados.

La filosofía materialista vitalista propuesta por Shiva (1997) propone "la recuperación de la tierra como materia viva que garantiza su supervivencia y la de sus semejantes (...) y vitalista, (puesto que) las mujeres se han ocupado de hacer las tareas de subsistencia; en otras palabras, las actividades de sostenibilidad de la vida humana o trabajos de cuidados, (y esto) ha originado un saber acerca del sostenimiento de la vida y (ha) otorga un valor a este saber". Estos saberes de la mujer son necesarios dado que la vida de la tierra y de todos los que habitamos en ella, es frágil y vulnerable. La mujer sostiene y cuida haciendo posible la existencia en medio de la incertidumbre.

En resonancia con lo expuesto anteriormente, el grupo de trabajo también se ha preguntado sobre el compromiso ético con la naturaleza. Si bien hemos notado que cuidamos de la naturaleza con respeto y amor cuando estamos cerca de ella, también somos conscientes del compromiso que debe tener el hombre habitando la tierra. Para Heidegger (1994), el hombre habita poéticamente la tierra, no porque haga poesía en el sentido literario, sino "porque tiene que crearse a sí mismo, tiene que darse forma, tiene que crear una cultura que le dé cobijo (...) Y la creación esencial y originaria, (...) es la creación de un sentido para su existencia, la imaginación de lo que en Sein und Zeit Heidegger llama la precomprensión del mundo y de sí mismo, el horizonte simbólico desde el cual el hombre se interpreta y bosqueja sus posibilidades de ser y que se encarna en el lenguaje". Heidegger habla del habitar poéticamente, y con ello nos da un sentido de pertenencia y de arraigo, que también nos identifica como habitantes de la Tierra.

Respondiendo a nuestra pregunta inicial, nos parece necesario seguir el llamado hecho por Vargas de una conciencia que incluya a todos los seres del mundo donde vivimos, pues todos tenemos los mismos derechos. La propuesta de Heidegger de crear un proyecto humano cultural de relaciones de interdependencia y de integridad en comunidad con todos, unida a la apuesta 
ética por la vida realizada por las mujeres como ética de la Tierra — siguiendo a Shiva - hace que sea un proyecto viable y una apuesta necesaria a realizarse en la vida cotidiana conciente, en donde la existencia prima sobre las lógicas de vida construidas en Occidente.

\section{Referencias}

Corredor, Álvaro Andrés (2011). Caminar. Entrevista con Isaías Román. Casa de Isaías en Bogotá.

Careri, Francesco. (2002). Walkscape: el andar como practica estética. Editorial Gustavo Gili. Barcelona.

Calvino, Italo. (1989). Seis propuestas para el próximo Milenio, Ediciones Siruela, Madrid.

Fulton, Hamish. Siete jornadas a pie desde y hasta punta mujeres. Caminando por carreteras veredas y senderos. Catálogo publicado por la Fundación César Manrique.

Guerrero, Patricio. (2011). Corazonar la dimensión política de la espiritualidad y la dimensión espiritual de la política. Alteridad 10. Revista de Ciencias Humanas, Sociales y educación, Universidad Politécnica Salesiana del Ecuador.

Guerrero, Patricio. (2010). Corazonar. Una antropología comprometida con la vida. Universidad Politécnica Salesiana del Ecuador. Quito.

Hernández Piñeros, Aranzazu. (2012). La apuesta política de Vandana Shiva: los saberes de las mujeres y la sostenibilidad de la vida. Revista Dilemata, Año 4, No.10. Zaragosa.

Le Breton, David. (1995). Antropología del cuerpo y la modernidad. Descripción de un estudio de Maurice Leenhardt sobre una tribu de Melanesia. Ediciones Nueva Visión. Buenos Aires.

Morgan, Robert C. (2003). Del arte a la idea, ensayos sobre arte conceptual. Ediciones Akal. Madrid.

Munévar, Dora Inés. (2006). Artes Vividas, despliegues en la vida cotidiana. Editado por la Universidad Nacional de Colombia, Bogotá.

Serres, Michel. (1995). Atlas. Editorial Cátedra, Madrid. Katsura.
Serres. Michel. (1984) El paso del noroeste, Hermes V. Paris, Minuit.

Vargas, Carlos Alfredo. (2011). Contrato ético con la naturaleza. Tesis par optar por el grado de Magíster en Estudios Amazónicos. Leticia. Sin publicar.

Vásquez, Adolfo. (2007). Joseph Beuys, “Cada hombre, un artista" Los Documenta de kassel o el Arte abandona la galería, en Revista Almiar. Margen cero. Disponible en: http://www.margencero.com/articulos/new/joseph_ beuys.html\#_ftn5. 